\title{
OS LIMITES DOS AUTOSSACRIFÍCIOS SEGUNDO MONTAIGNE*
}

\author{
Lúcio $\mathrm{Vaz} * *$ \\ lucio.oliveira@ufes.br
}

\begin{abstract}
RESUMO O texto propõe, inicialmente, uma aproximação entre as visões de Aristóteles e Montaigne sobre a virtude da coragem, com especial atenção ao problema da morte heroica. Então, são apresentados alguns pontos de diferenciação do filósofo francês em relação ao legado aristotélico para, enfim, mostrar que uma das restrições especificamente montaignianas sobre a legitimidade de um ato de coragem acarreta uma limitação à ação do próprio Estado, o que deve ser julgado um elemento essencial à formação do pensamento político moderno.
\end{abstract}

Palavras-chave Morte, coragem, Aristóteles, Montaigne.

ABSTRACT At first, the article proposes an approximation between Aristotle's and Montaigne's views on the virtue of courage, with special attention to the problem of heroic death. Then, some distinguishing points of the French philosopher from the Aristotelian legacy are presented, in order to show, finally, that one of the specifically Montaignean restrictions on the legitimacy of an act of courage entails a limitation to the action of the State itself; which must be considered an essential element to the shaping of Modern political thought.

Keywords Death, Courage, Aristotle, Montaigne.

* Este texto integra projeto de pesquisa financiado pelo CNPq. Artigo submetido em 22/11/2017. Aceito em 04/01/2018.

** UFES - Universidade Federal do Espírito Santo, Vitória, ES, Brasil.

KRITERION, Belo Horizonte, nº 141, Dez./2018, p. 809-825 


\section{I}

Minha proposta, neste artigo, consiste em debater um conceito e uma problemática nos Ensaios, de Michel de Montaigne (1533-1592): o autossacrifício. Meu recorte textual, para tanto, não está centrado nesse ou naquele capítulo do livro, mas se propõe uma análise diagonal das diversas ocorrências do conceito na obra. O termo 'autossacrificio' não tem um correspondente único e claramente identificável nos "Ensaios", no "Diário de viagem", de Montaigne, nem nos escritos de Aristóteles. Entretanto, acredito que essa palavra me permite delimitar uma zona conceitual que é debatida por esses autores. Por 'autossacrificio', intenciono significar a escolha da morte ou, pelo menos, a sua aceitação por parte de um agente sendo tal escolha necessária à consecução de um fim em favor de outras pessoas, ao passo que o suicídio consiste na mesma escolha motivada pelo desejo de se livrar de um mal ou de buscar um bem maior para si mesmo. $\mathrm{O}$ ato de coragem ou de heroísmo, mais especificamente, é o autossacrifício acompanhado e motivado pela virtude da coragem e constitui um ponto de imbricação entre, por um lado, motivações, valores e normas éticas da esfera individual e, por outro, exigências da virtude cívica e da vida pública e coletiva.

Montaigne não dedica a esses conceitos, até onde posso ver, qualquer expressão fixa. Todavia, discorre várias vezes sobre o tema do sacrifício e por ele, como todo nobre de seu tempo, ${ }^{1}$ nutre grande interesse. A defesa da coragem, até onde posso perceber, não sofre a mesma variação de posicionamento que ocorre ao longo das camadas de escrita dos "Ensaios" quanto ao ideal de preparação da morte. ${ }^{2} \mathrm{O}$ tema é tocado em muitos capítulos e abundam situações e atitudes tidas por exemplares ao longo de toda a obra, conquanto - como procurarei mostrar - as restrições mais tipicamente montaignianas à realização de autossacrifício estejam, precipuamente nas camadas B (edição de 1588) e na C (entre 1588 e 1592). Algumas ocorrências dos termos 'coragem'e 'valentia' exibem um uso não apenas destinado a se referir à virtude propriamente dita, mas também aos vícios por excesso ou por escassez - uso esse acompanhado por expressões de gradação ou similares. Exemplos disso são aqueles em que Montaigne fala de uma "coragem acima da razão", ${ }^{3}$ de uma "coragem fora de lugar" ou de "coragens medrosas". 5

Cf. Boon, 1971. Boon realça especialmente o fato de que Montaigne se via como nobre e que isso teria reflexos na filosofia dos "Ensaios".

2 Procurei explorar esse ideal em Vaz (2011).

3 Montaigne, I, 24, p. 128A: "[...] et qui grossissent leur courage au-dessus de la raison." Nas citações que fizer dos Ensaios, o primeiro número, em algarismo romano, refere-se ao livro; o segundo, ao capítulo; e o terceiro, à página, seguida da letra que diz respeito ao estrato do texto: A, para as edições de 1580 e 1582; $\mathrm{B}$, para as inovações da edição de 1588 e C, para as posteriores a essa data.

5 "Et par ce que telles impressions rendent les courages craintifs, il deffend en ses loix toute instruction de telles menaces [...]", II, 12, p. 438. 
Podemos dizer que, de forma geral, antigos e renascentistas acreditavam "que a conquista da fama imortal era a marca externa da virtude e expressão da realização mais perfeita da excelência humana." (Araújo, 2008, p. 10). Já foi salientado insistentemente por diversos comentadores - Villey, Tenenti, Sérgio Araújo - que Montaigne se distancia tanto do molde cristão de entender a glória divina dos humanos quanto de algumas das presunções do humanismo italiano. Segundo Araújo, as motivações para a desconfiança de Montaigne são várias, entre elas: sua aversão natural e a inspiração helenista (Araújo, 2008, p. 10-11). Montaigne, para Araújo, teria dado continuidade a um processo de subjetivação da ética, ao desconfiar dessas marcas exteriores. A vida recolhida ter-lhe-ia permitido melhor o exercício da liberdade, pelo menos, sobre si próprio: "A solidão me parece ter melhor aparência e mais sensatez àqueles que deram ao mundo sua idade mais ativa e florescente [...]". ${ }^{6}$

$\mathrm{Eu}$ acrescentaria a essas motivações certa suspeita de ordem política que concerne à vinculação do indivíduo com a organização coletiva, notadamente, sobre os usos que uma coletividade (ou um governante) pode fazer de um indivíduo e sobre os usos que os indivíduos podem fazer dos ideais coletivos - o que procurarei deixar mais claro ao fim deste artigo.

A tão frequentemente referida aversão natural de Montaigne à turba da vida cotidiana e ao exibicionismo na busca de glória é um dos aspectos que contribuem para um caráter reflexivo e retirado. Contudo, a tendência natural ao recolhimento e à quietude são pouco ante uma motivação que perpassa os "Ensaios" - o exercício do julgamento como ato de liberdade e, mais que isso, de libertação contínua. Essa conexão estreita entre afirmação da liberdade e retirada à vida privada é relida por Felicity Green em termos de um cuidado de si, nos moldes do estoicismo de Sêneca, reinterpretado à luz de Foucault (Green, 2012, p. 110).

Para Montaigne, suas exteriorizações em atos não esgotam o que ele é. São seus pensamentos que testemunhariam muito mais acerca disso. ${ }^{7}$ É à dimensão interior que devemos submeter a avaliação última de nossas ações e também é na interioridade que encontramos consolo para as perdas:

Não é para a aparência que nossa alma deve desempenhar seu papel, é em nós, lá dentro, onde nenhum olho se oferece além dos nossos: lá onde ela nos cobre do medo

6 Montaigne, I, 38, p. 242C: "La solitude me semble avoir plus d'apparence, et de raison, à ceux qui ont donné au monde leur aage plus actif et fleurissant [...]". (Todas as traduções são minhas).

7 Montaigne, II, 6, p. 379C: "Les effects diroyent plus de la Fortune que de moy. Ils tesmoignent leur roole, non pas le mien, si ce n'est conjecturalement et incertainement: eschantillons d'une montre particuliere." Sobre isso, ARAÚJO, 2008, p. 103. 
da morte, das dores e até da vergonha; ela nos assegura aí da perda das nossas crianças, de nossos amigos e de nossas fortunas e, quando a oportunidade aí se apresenta, ela nos conduz também aos riscos da guerra. ${ }^{8}$

Distinguindo-se do recolhimento e do exercício de liberdade interior, porém não os contradizendo, encontramos também nos Ensaios a constatação de que há uma carência radical dos outros. Isso já se encontra parcialmente detectado na própria decisão de se fazer lembrar pelos seus "parentes e amigos" por meio da escrita - algo manifesto já no prefácio "Ao Leitor", conquanto circunscrito a essa esfera doméstica. Também no ensaio sobre a conversação, Montaigne vê, no estabelecimento de vínculos dialógicos, algo natural e indispensável a uma vida humana. ${ }^{9} \mathrm{E}$ a maior realização de uma carência de outrem sem que nisso se deva ver um aprisionamento do si mesmo seria indubitavelmente a amizade com La Boëtie. ${ }^{10}$ Merleau-Ponty afirma com precisão: "O mesmo autor que queria 'viver segundo si mesmo' experimentou apaixonadamente que nós somos, entre outras coisas, aquilo que somos para os outros e que a opinião deles nos atinge no centro de nós mesmos." (Merleau-Ponty, [1960], p. 1358). Não há contradição entre essas duas faces, porquanto o juízo crítico sobre si e sobre os conteúdos dos próprios anseios de reconhecimento intersubjetivo permanece em atuação. Sobre essa coerência, realça Sérgio Araújo:

O reconhecimento da naturalidade dessa ambição [da glória], após a afirmação da sua crítica, longe de funcionar como ponto de partida para a consolidação de um sentido ético positivo para a glória, atualizava seu desígnio fundamental, ou seja, de assegurar a plena liberdade de seu jugement, tomando seus próprios enunciados como objetos de questionamentos e de reconsiderações. (Araújo, 2008, p. 75).

Sabendo da clivagem clara que Montaigne pretende traçar entre público e privado, ${ }^{11}$ qual seria sua visão a respeito desses atos em que a vida do indivíduo e eventualmente a segurança do público estão em jogo? Enquanto em alguns ensaios, notadamente no "Costume da Ilha de Quíos", Montaigne debate eventuais razões para não abdicar da vida, os textos que procurarei analisar aqui expõem

8 Montaigne, II, 16, p. 623A: "Ce n'est pas pour la montre que nostre ame doit jouer son rolle, c'est chez nous, au dedans, où nuls yeux ne donnent que les nostres: là elle nous couvre de la crainte de la mort, des douleurs et de la honte mesme; elle nous asseure là de la perte de nos enfans, de nos amis et de nos fortunes, et, quand l'opportunité s'y presente, elle nous conduit aussi aux hazards de la guerre."

9 "Le plus fructueux et naturel exercice de nostre esprit, c'est à mon gré la conference." (III, 8, p. 922B e seguintes).

10 Além da declaração sobre suas vivências e sentimentos acerca do amigo, é digno de menção um comentário mais geral: "II n'est rien à quoy il semble que nature nous aye plus acheminé qu'à la societé." (I, 28, p. 184A). A respeito dessa relação reconsiderada com a alteridade, remeto a leitora a Starobinski, 1982, cap. 3.

11 Montaigne, I, 23, p. 118A; III, 10, "De Mesnager sa Volonté". 
e confrontam razões para trocá-la por algo de supostamente maior valor. Mas, pelo quê valeria a pena trocar a vida?

\section{II}

As obras de Aristóteles nas quais o assunto da coragem é mais detidamente tratado são a "Ética a Nicômaco" (III, a partir de 1115a5) e a Ética a Eudemo. Inserida dentro da teoria geral da virtude, a coragem opõe-se aos extremos da covardia e da temeridade. Várias características são coordenadamente apresentadas como critérios na diferenciação dessas três disposições da vontade.

Tal diferenciação permite uma definição, com o grau de inexatidão próprio à ética, de condições de realização de um ato de coragem ("Ética a Nicômaco", III, 1116A10-15). A seguir arrolo as referidas características fundamentais: primeira, eficiência. É necessário que o ato corajoso seja devidamente capaz de chegar até o fim, sendo igualmente necessário que o agente seja capaz de desempenhar a ação. Como contraexemplo ilustrativo, imagine uma pessoa que não saiba nadar e se arrisca para salvar sua pequena sobrinha de um afogamento. Ela seria inconsequente, pois provavelmente ambos morreriam. A prudência deve atuar na avaliação, tanto quanto nos é possível, racional do perigo, na contenção do ímpeto de salvar ou de auxiliar outrem, quando os riscos o sobrepujam.

Segunda, conhecimento. Aquele que pratica uma ação sem o conhecimento de seus efeitos, riscos e (ou) fins não pode ser predicado corajoso e seu ato não pode ser julgado de heroísmo, ainda que tenha sido eficiente.

Terceira, necessidade, ou seja, não se arriscar se não for necessário. Como exemplos não válidos de atos de heroísmo por não satisfazerem esse requisito, temos os casos de grandes heróis televisivos que buscam o risco sem nenhum bom motivo diante da plateia dos que não se arriscariam mesmo que tivessem algum. Mas o que podemos julgar como real e fundamentalmente necessário? Diz o estagirita: coisas belas, nobres, elevadas, "que são virtudes ou ações que emanam das virtudes" ("Ética a Nicômaco", 1115a30; "The Eudemian Ethics", VIII, 1248b35), são a finalidade maior da ação.

Qualquer ato de risco sem tais condições de realização constitui temeridade e qualquer agente que, dadas tais condições, não se arrisca será classificado, segundo Aristóteles, de covarde. Enquanto a temeridade constitui um avanço excessivo e impensado na ação, a covardia se mostra um recuo excessivo. Dizendo de outro modo, a covardia consiste num temor daquilo que não deve ser temido e a temeridade, num destemor daquilo que deve ser temido ("Ética a Nicômaco", 1115a10; "The Eudemian Ethics", II, 1221a10-15). O covarde ousa de menos e o temerário ousa demais ("Ética a Nicômaco", 1107a33, 1116a5- 
10; "The Eudemian Ethics", III, 1228a30-35). A morte deve, com certeza, ser arrolada como a mais temível de todas as coisas, por ser destrutiva da vida ("Ética a Nicômaco", 1115a25; "The Eudemian Ethics", III, 1229a30-1229b10), mas até a morte é tida na devida conta pelo homem corajoso e, sem superestimá-la nem subestimá-la, não a toma como o mais alto mal.

No discernimento entre situações dignas de risco e não dignas, entre coisas dignas de temor e as não dignas, é a razão que ocupa o papel central no pensamento ético de Aristóteles.

A explicitação das condições de ocorrência da virtude da coragem e sua consequente contraposição à temeridade e à covardia propiciam a Aristóteles uma percepção sobre cinco aparentes formas de coragem, quais sejam: a coragem militar obrigatória e as provindas do sucesso ocasional, da ignorância, da "força da emoção" e da confiança desmesurada ("Ética a Nicômaco", 1116a15-1117a25). Parece-me que a marca comum a todas as cinco é uma impropriedade na motivação da ação: a mera obrigação legal, a experiência afortunada e fortuita no enfrentamento dos perigos, a intoxicação por vinho, a paixão desmedida e assim por diante. Assim, qualquer uma delas pode ser uma ação corajosa, mas apenas por acidente e não por si mesma ("The Eudemian Ethics", VIII, 1279a10).

E afinal por que se arriscar? Aristóteles afirma que o homem bom pode dar a vida pelos amigos porque o prazer que extrai de uma ação nobre em pouco tempo é muito intenso. Tal prazer seria preferível a um tempo extenso de uma vida medíocre. ${ }^{12}$ Essa consideração reforça a ideia de que o prazer tem sua relevância na ética de Aristóteles, porém esse prêmio parece ser não apenas um acompanhamento do ato virtuoso, mas também seu guia.

Aristóteles é, sem dúvida, a principal influência no tratamento da coragem nos "Ensaios", conquanto a pletora de exemplos sobre atos corajosos tenha sido colhida por Montaigne em um leque muito amplo de autores e situações concretas de seu tempo e de sua vida. Arrisco-me a afirmar até mesmo que o tema da coragem culmina, juntamente àquele da amizade, como um dos momentos mais aristotélicos da escrita de Montaigne.

Acredito que Montaigne, calcado na filosofia moral aristotélica, debruçase sobre o problema do sacrifício particularmente por meio de duas questões subsidiárias: primeira, quais as circunstâncias de emprego da coragem, ou seja, sob quais condições seria admissível a possibilidade de morte do agente? Segunda: quais as motivações moralmente legítimas para o desempenho dessa ação? 
Sem dúvida, Montaigne admira em alto grau aqueles cuja coragem faz arriscarem a própria vida. A coragem para Montaigne seria, no dizer de Thibaudet, uma "arte poética" "[...] de sustentar a vida como um magnífico desafio contra a morte." (Thibaudet, 1963, p. 197). Muitos homens, entre os quais Montaigne também se inclui, prefeririam a honra à vida ${ }^{13}$ e é clara sua admiração por aqueles cuja coragem (vaillance) faz arriscarem a própria vida (I, 31, p. 211A). A importância da valentia militar reside na possibilidade de vazão do vigor e do companheirismo, mas também e sobretudo, na defesa da coletividade:

Não há ocupação prazerosa como a militar, ocupação tanto nobre na execução (pois a mais forte, generosa e suprema de todas as virtudes é a coragem) quanto nobre em sua causa: não há utilidade mais justa, nem mais geral do que a proteção do descanso e da grandeza de seu país. ${ }^{14}$

No entanto, daí não decorre, como bem lembra Bonadeo (1985, p. 417), que Montaigne esteja aquiescendo com toda e qualquer guerra, simplesmente por ser guerra. A maior das virtudes é a "valentia militar", mas importa acrescentar: abaixo da constância filosófica (II, 7, p. 382A).

A condição fundamental para a moralidade de toda ação virtuosa deliberação ou voluntariedade - também é um requisito para o ato de heroísmo. Deverá ser um dever, livremente assumido pelo próprio agente. O risco da vida deve suceder apenas por escolha - e não por obrigação externamente imposta - e a honra encontra-se em ações livres (III, 9, p. 967B). Como o autor dos Ensaios acentua em todo o livro, o que confere valor moral ao ato de coragem é uma viva motivação interior e não uma obrigatoriedade provinda de fora; o que já foi minuciosamente analisado por Aristóteles na "Ética a Nicômaco" (particularmente, no livro IV). Assim, a coragem militar obrigatória não necessariamente, e nem sempre, se traduz em "coragem filosófica". ${ }^{15}$

A virtude também se distingue de uma perspectiva exclusivamente voltada ao ganho. De um modo geral, Montaigne crê que, se nos lançamos a relações interpessoais por meio de favores, estamos nos assujeitando sub-repticiamente.

13 Montaigne, III, 9, p. 966B: "Combien de galans hommes ont mieux aimé perdre la vie que la devoir [...] Je ne trouve rien si cher que ce qui m'est donné et ce pourquoy ma volonté demeure hypothequée par tiltre de gratitude".

14 "II n'est occupation plaisante comme la militaire; occupation et noble en execution (car la plus forte, genereuse et superbe de toutes les vertus est la vaillance), et noble en sa cause: il n'est point d'utilité ny plus juste, ny plus universelle que la protection du repos et grandeur de son pays." (III, 13, p. 1097B).

15 Como bem diz Butor (1968, p. 50-51), baseando-se no II, 7, p. 382A: “il n'est aucune des vertuz qui s'espende si aysement que la vaillance militaire. II y en a une autre, vraye, perfecte et philosophique”. 
Nada encontro de tão caro quanto aquilo que me é dado: é por isso que minha vontade permanece hipotecada por título de ingratidão e recebo mais de bom grado as funções que estão à venda. Creio firmemente que por essas eu nada mais dou do que dinheiro; pelas outras, eu me dou a mim mesmo. ${ }^{16}$

Ao contrário de Green (2012, p. 101), não acredito que essa passagem testemunhe um espírito aristocrático, em contraposição ao burguês, pois ela denota uma relação (eventualmente burguesa) daquele que aceita algo pelo mérito, e um mérito que não se alcança pela força das armas, nem insígnes de distinção estamental (como filiação, por exemplo), mas pelo pagamento.

Em coerência a esse plano de relações, que pode ser doméstico, Montaigne, no plano político, diz que o respeito que devemos aos governantes se justifica pelo simples fato de desempenharem a função em que foram colocados e não se mede pela sua capacidade de satisfação dos interesses pessoais: "Devemos a sujeição e a obeidiência igualmente a todos os reis: pois ela diz respeito à função deles; mas a estima, assim como a afeição, só a devemos à virtude deles." ${ }^{17}$ Tanto nas relações entre as pessoas comuns quanto naquelas entre o governante e os seus súditos, a doação de si parece exigir, sub-repticiamente, ações compensatórias por parte dos beneficiados. Daí não decorre que Montaigne não acate absolutamente nenhum ato de "doação de si", porém ele levanta suspeitas sobre aqueles que o fazem na expectativa de atenderem interesses pessoais (e, tanto pior, não explícitos e declarados):

Mas não se deve chamar dever (como fazemos todos os dias) uma agrura e aspereza intestina que nasce do interesse e da paixão privada; nem coragem, uma conduta traidora e maliciosa [...] não é a causa que lhes impele, é o seu interesse; eles atiçam a guerra não porque ela seja justa, mas porque é guerra. ${ }^{18}$

O ímpeto pelo interesse individual e, particularmente, pelo renome individual pode chegar ao ponto de ser prejudicial à coletividade, nomeadamente quando ele se oferece para justificar a própria aventura bélica.

16 Montaigne, III, 9, p. 966: “Je ne trouve rien si cher, que ce qui m'est donné: et ce pourquoy, ma volonté demeure hypothequée par tiltre d'ingratitude: Et reçois plus volontiers les offices, qui sont à vendre. Je croy bien: Pour ceux-cy je ne donne que de l'argent: pour les autres, je me donne moy-mesme."

17 Montaigne, I, 3, p. 16C: "Nous devons la subjection et obeïssance egalement à tous Rois: car elle regarde leur office: mais l'estimation, non plus que l'affection, nous ne la devons qu'à leur vertu."

18 Montaigne, III, 1, p. 793B: "Mais il ne faut pas appeller devoir (comme nous faisons tous les jours) une aigreur et aspreté intestine qui naist de l'interest et passion privée; ny courage, une conduitte traistresse et malitieuse. [...] ce n'est pas la cause qui les eschauffe, c'est leur interest; ils attisent la guerre non par ce qu'elle est juste, mais par ce que c'est guerre." 
Quanto às restrições próprias às delimitações sobre a própria virtude da coragem, Montaigne aparenta, mais uma vez, repetir a análise de Aristóteles. ${ }^{19}$ Na visão do estagirita, bem como na de Montaigne, um dos extremos dos quais a coragem se distancia é a temeridade, ou seja, a precipitação em não avaliar o risco de não-efetivação do ato. ${ }^{20}$ Em contraposição ao que age temerariamente, aquele que toma em consideração os perigos está menos sujeito a eles e, precatando-se contra a morte, não o faz por temê-la. Como exemplo, Montaigne em alguns trechos dos Ensaios elogia a coragem de Sócrates, que, até mesmo recuando em guerra, soube avaliar os perigos e arremata: "Nosso povo está errado em dizer: aquele teme a morte, quando quer exprimir que ele pensa nela e que a prevê". ${ }^{21} \mathrm{Na}$ outra ponta, situa-se a covardia, extremo de escassez do que se destaca a coragem ou, para lembrar a expressão mencionada há pouco, uma "coragem medrosa".

\section{III}

Levando à frente nossa leitura, notamos, contudo, algumas diferenças da posição montaigniana em relação à expressa na Ética a Nicômaco e na Ética a Eudemo. Para Montaigne, todas as virtudes têm limites e eles vão além da mediania interna à virtude, diferentemente do que pensa a tradição aristotélica. E é em contraposição à opinião aristotélica que Montaigne defende que afirmar não ser possível haver excessos na própria virtude é um mero jogo de palavras. Aspereza e violência, por exemplo, seriam motivações na adoção de uma ação virtuosa que a tornam desmesurada:

Podemos tomar a virtude de forma que ela se torne viciosa, se a abraçamos com um desejo demasiado áspero e violento. Aqueles que dizem que jamais existe excesso na virtude na medida em que não mais é virtude se aí existe excesso estão brincando com as palavras. ${ }^{22}$

Talvez não se trate de um deslize de compreensão da terminologia por parte do ensaísta, porém de um posicionamento contrário à tenacidade e à brutalidade interiores que podem ser vinculadas ao assentimento e seguimento dos preceitos

19 Montaigne, I, 15, p. 68A. É curioso que logo em seguida a esse ensaio sobre os excessos (temeridade), venha um texto sobre a escassez (covardia). Outras ocorrências sobre a coragem: I, 12 ("De la constance").

20 Exemplos em torno dessa questão, nos Ensaios, encontram-se nos capitulos I, 5 e I, 6.

21 "Notre peuple a tort de dire: celuy-là craint la mort, quand il veut exprimer qu'il y songe et qu'il la prevoit." (III, 6, p. 900B). Cf. Aristóteles, "Ética a Nicômaco", III, 1115A20-1115B1.

22 Montaigne, I, 30, p. 197A: "Nous pouvons saisir la vertu de façon qu'elle en deviendra vicieuse, si nous l'embrassons d'un desir trop aspre et violant. Ceux qui disent qu'il n'y a jamais d'exces en la vertu, d'autant que ce n'est plus vertu si l'exces y est, se jouent des parolles." 
da virtude (ou, pelo menos, do que se configurou historicamente como verdade na época de Montaigne). Não podemos dizer que Montaigne estaria, com isso, defendendo que a prática da virtude pode eventualmente incluir excessos, mas sim que a vinculação exagerada e talvez passional às regras da virtude - como ocorre ao manifestarmos um desejo de punição (exemplos citados no mesmo trecho ${ }^{23}$ ) contra as ações não virtuosas - é um erro moral ou gera erros morais. Aqui é proveitoso o juízo geral que Felicity Green profere sobre um ânimo motivador dos Ensaios, a qual se baseia, por sua vez, nos trabalhos de David Quint. Ela diz: "Independência, constância e firmeza são repudiados como elementos de um estoicismo obstinado, violento e impiedoso: o exercício do poder sobre o si mesmo, para Montaigne, acarreta tanto a crueldade com os outros quanto consigo mesmo." 24

Com a até então excessivamente enaltecida coragem ocorre o mesmo. A valentia (palavra não necessariamente usada em oposição a 'coragem') deve ser limitada. Há excessos de bravura militar que não se assemelhariam propriamente a um exagero temerário (qual seja o desejo de se submeter desnecessariamente a provações e situações adversas). ${ }^{25}$ Contudo, esses exemplos ainda funcionariam perfeitamente dentro dos quadros delimitados pela filosofia de Aristóteles: temeridade e não coragem.

Resta saber se Montaigne ainda acompanha o filósofo grego quanto à segunda pergunta que nos formulamos há pouco: quais as motivações legítimas para a execução de um ato de coragem o qual pode causar, no limite, a morte do próprio agente?

\section{IV}

O filósofo bordelês, nesse tópico da coragem como em outros de seus "Ensaios", vaga pelo tema exibindo sua desconfiança sobre os extremos, as ilusões e vaidades que os homens constroem a respeito de uma virtude tida por

23 "Ny la mere de Pausanias, qui donna la premiere instruction et porta la premiere pierre à la mort de son fils, ny le dictateur Posthumius, qui feit mourir le sien que l'ardeur de jeunesse avoit poussé heureusement sur les ennemis" (I, 30, p. 197C).

24 Green, 2012, p. 146: "Independence, constancy and firmness are repudiated as elements of an obstinate, violent and unforgiving Stoicism: the exercise of power over the self, for Montaigne, results both in cruelty to others and to oneself."

25 Os exemplos são citados no II, 2, após o que Montaigne comenta: "[...] qui ne juge que ce sont boutées d'un courage eslancé hors de son giste? Nostre ame ne sçauroit de son siege atteindre si haut. II faut qu'elle le quitte et s'esleve, et, prenant le frein aux dents, qu'elle emporte et ravisse son homme si loing qu'apres il s'estonne luy-mesme de son faict" (p. 347A). Também um capítulo é dedicado ao tema, o I, 15, particularmente no início (p. 68): "La vaillance a ses limites, comme les autres vertus: lesquels franchis on se trouve dans le train du vice; en maniere que par chez elle on se peut rendre à la temerité, obstination et folie, qui n'en sçait bien les bornes: malaiseez en verité à choisir sur leurs confins." 
muitos como a maior de todas. Todavia, sua rejeição dos extremos não o conduz a uma demarcação criteriosa de fronteiras entre o razoável e desrazoável, entre o válido e o inválido.

Do ponto de vista metodológico, se assim podemos dizer, a análise das intenções é de suma importância para o filósofo francês, em consideração ao fato de que é a vontade que está em nosso poder e que qualquer regra do dever se aplica a ela. ${ }^{26}$ Quanto ao problema das motivações e justificações dos atos de heroísmo, Montaigne exibe sua perspicácia antropológica para a diversidade humana e a utilidade social das crenças. ${ }^{27} \mathrm{~A}$ dos beduínos, por exemplo, de que os que morrem pela pátria reencarnam em melhores corpos é útil (II, 16, p. 630A), embora não, digamos com Aristóteles, virtuosa. Não obstante, como a utilidade social e política não implica critério de ação virtuosa, Montaigne não se limita a essa abordagem meramente descritiva e critica aqueles que praticam atos de coragem estritamente objetivando a glória. ${ }^{28}$ Uma das justificações e motivações mais comuns seria a esperança de recompensas na vida pós-morte (a glória divina) - esperança da qual o pensador de Bordéus não se vale, ao contrário do que fizera a tradição cristã. Poderíamos, inclusive, afirmar que, em sua visão, uma das fronteiras ao emprego legítimo da coragem seria a superstição ou alucinação na adesão a uma crença. ${ }^{29} \mathrm{O}$ faro de Montaigne é assaz acurado para perceber a força que as mais esdrúxulas causas podem exercer sobre os homens a ponto de fazê-los morrer por elas e vê com desconfiança a realização de um ato virtuoso motivado pela crença e esperança na recompensa em outra vida. Exemplo disso é a passagem, já referida neste artigo, em que Montaigne percebe a utilidade da crença na vida pós-morte pelos beduínos, mas não a chama de "vã". ${ }^{30}$ Montaigne critica aqueles que se fiam na glória (seja divina, seja terrena) para realizar ações corajosas. Conquanto a glória, ou antes, o desejo dela seja um traço ínsito em nossa natureza e não possamos nos desvencilhar inteiramente dele (II, 16, p. 619-20A), a virtude não pode depender dela, pois não

26 "Que l'intention juge nos actions" (I, 7, pp. 30-31).

27 O que é visível em I, 14, p. 53, onde exemplos e constatações são citados sem que Montaigne opine a respeito.

28 Vaga, imprecisa e, sobretudo, falsa é a opinião de Friedrich (1949, p. 325) de que a renúncia da glória como objetivo seja reflexo em Montaigne de uma percepção da morte como parte de sua individualidade.

29 Montaigne, I, 14, p. 52A: "Un valet à Thoulouse, accusé d'heresie, pour toute raison de sa creance se rapportoit à celle de son maistre, jeune escholier prisonnier avec luy; et ayma mieux mourir, que se laisser persuader que son maistre peust faillir." Sobre uma atitude de distanciamento a respeito do assentimento de uma maneira geral, vale citar: "Et suis l'advis de sainct Augustin, qu'il vaut mieux pancher vers le doute que vers l'asseurance és choses de difficile preuve et dangereuse creance" (III, 11, p. 1032B).

30 Montaigne, II, 16, p. 630A. Tenenti (1957, pp. 21-43) traça um interessante histórico do embate entre a glória divina, cristã, e a retomada da glória romana no Renascimento. 
raro a coragem é necessária, mesmo sem uma plateia. ${ }^{31}$ "A mais curta maneira de chegar à glória seria fazer por consciência o que fazemos pela glória". ${ }^{22}$

Só resta, então, ao autor dos "Ensaios" atribuir aos atos de coragem um valor intrínseco: a justificação de uma ação corajosa é tê-la feito ${ }^{33}$ ou, dito de modo mais exato, justificá-los independentemente da satisfação de um interesse pessoal do agente. Assim, entre as notas características desse risco de morte justificado, encontram-se o enfrentamento do acaso ${ }^{34}$ e o destemor da morte (II, 16, p. 623A). Não se deve fundar a virtude na esperança das recompensas de outrem (III, 2, p. 807B). Para esclarecimento desse ponto, Montaigne serve-se da metáfora do marinheiro: independentemente da vontade de Deus em tomar-lhe a vida ou não, ele permanece conduzindo o timão corretamente (II, 16, p. 624B).

V

Notamos no texto montaigniano claras restrições quanto à veracidade ou verossimilitude das crenças pelas quais alguém se permite a morte. Em um trecho digno de curiosidade não apenas para a questão da coragem como também para o tema da religião, Montaigne chega a afirmar que o mártir pode ser um louco tendo alucinações. ${ }^{35} \mathrm{O}$ mártir oscilaria, na classificação das cinco pseudocoragens de Aristóteles, entre aquela provinda da esperança e a movida por emoções irracionais.

Em outra passagem, ${ }^{36}$ no entanto, Montaigne parece, pelo menos em um primeiro olhar, defender uma valorização da coragem em arriscar a vida por um ideal ou, até mesmo, por um sonho. Os exemplos dados por Montaigne no trecho são, todavia, estranhos (como um rei que se mata fiando-se nos augúrios do latido de cães), o que nos faz suspeitar que sua frase "Abandonar a vida por um sonho é valorizá-la com justiça pelo que ela é” seja irônica. Uma ironia que

31 Montaigne, II, 16, p. 622 A. E Montaigne se declara mais conforme à natureza de L. Thorius Balbus que não buscava a grandiosidade da glória, apesar de preparado para morrer em batalha: III, 7, p. 917C. Konstantinovic (1989, pp. 75-76) acredita que a temática do heroi desconhecido, tão importante para Montaigne, já era recorrente nas "Vidas dos Homens llustres", de Plutarco.

32 Montaigne, III, 2, p. 807-808B "La plus courte façon d'arriver à la gloire, ce seroit faire par conscience ce que nous faisons pour la gloire".

33 Montaigne, II, 16, p. 629C. Leia-se com proveito também o II, 7 (Des récompenses d'honneur), onde Montaigne critica a atribuição por parte dos governos de vantagens além de signos e condecorações aos cidadãos corajosos (p. 381A).

34 Montaigne, II, 16, p. 623 A, sem que esse enfrentamento acarrete pleno domínio: "C'est imprudence d'estimer que l'humaine prudence puisse remplir le rolle de la fortune." III, 8, p. 934B. A virtude vence, ainda quando abatidos pelo acaso, como no caso dos ameríndios: I, 31, p. 211A.

35 Como bem o nota, com outros objetivos, Brahami, 2001, p. 62, citando II, 12, p. 566.

36 Montaigne, III, 4, p. 839B: "C'est priser sa vie justement ce qu'elle est, de l'abandonner pour un songe." Diferente da minha suspeita de ironia é a opinião de Bencivenga (1990, p. 90). 
se dirige ou à vida de quem o faz, porque eventualmente ela não vale muito, ou sobre o sonho, pensamento fútil que leva alguém a tamanho extremo.

Ao contrário dessa fina e sutil ironia, Montaigne é bastante claro na desaprovação do assassínio e da crueldade praticados em nome de uma crença, mesmo ou tanto mais, de uma crença religiosa. Acredito que aqui haja uma originalidade do filósofo francês sobre o autor da "Ética a Nicômaco". De modo geral, todo uso da força ou inflição de sofrimento que ultrapassem o necessário à defesa de si ou de um Estado são condenados por Montaigne como desmesurados e cruéis. A coragem atua diante da resistência do inimigo, ao passo que a crueldade, que é uma "coragem maliciosa", abusa da debilidade de forças daquele que já é uma presa ${ }^{37}$ ou pratica atos violentos movido por interesses escusos e estritamente pessoais. ${ }^{38} \mathrm{O}$ mesmo comedimento, prudência e clareza devem ser empregados na ponderação dos riscos com que alguém se oferece à morte por algo ou outrem.

Embora Montaigne condene vários exemplos como esses de sacrifício pessoal, não fornece, como já disse, um critério muito bem definido para distinguir causas válidas de não válidas. A imprecisão nas nossas delimitações conceituais se processa também no que concerne ao problema do momento oportuno. Assim como na questão do suicídio, o problema da oportunidade da morte num ponto na linha da vida se coloca: seria agora o melhor momento de emprego de minha morte? Montaigne responde: cada momento de risco de morte do qual covardemente se foge avilta a vida como um todo: "Quem toma sua morte por mal empregada se não há uma ocasião marcada para ela, em vez de tornar sua morte ilustre, obscurece conscientemente sua vida, deixando escapar, contudo, muitas justas ocasiões de se arriscar". ${ }^{39}$ A menos que aquele que se dispõe a não se arriscar num dado momento (uma batalha, por exemplo) tenha em vista outra oportunidade concreta e mais nobre, empurrar sempre para frente o momento oportuno de oferecer a própria vida seria, então, uma manifestação do vício da covardia.

É conhecido que Montaigne, no ensaio "Do útil e do honesto", toma certo distanciamento crítico na concessão à nascente razão de Estado, ao dizer que o próprio Montaigne não se encaixaria na função de alguém que deve temporariamente suspender suas convicções morais no caso de um conflito com exigências da segurança e da estabilidade coletiva. Montaigne diz que

37 Montaigne, II, 27 (Couardise mere de la cruauté), p. 693A e B.

38 Montaigne, III, 1, p. 793B, trecho já citado acima.

39 "Qui tient sa mort pour mal employée si ce n'est en occasion signalée, au lieu d'illustrer sa mort, il obscurcit volontiers sa vie, laissant eschapper cependant plusieurs justes occasions de se hazarder." II, 16, p. 623C. 
deveríamos deixar o desempenho desses encargos a quem é mais flexível, assim como os governantes carecem de cidadãos dispostos a se sacrificarem incondicionalmente:

[B] O bem público requer que se traia e que se minta [C] que se massacre. [B] Destinemos essa missão a pessoas mais obedientes e flexíveis. [B] É necessário deixar atuar essa parte aos cidadãos mais vigorosos e menos receosos os quais sacrificam sua honra e sua consciência, assim como aqueloutros antigos sacrificaram sua vida para a salvação de seu país. ${ }^{40}$

Esse último elemento da comparação é descrito de modo ainda mais claro quando Montaigne ajuíza que nenhum monarca aceita homens livres, que não os serviriam de maneira irrestrita:

Não quero ser tomado servidor nem tão afeiçoado nem tão leal que não se ache por bem trair ninguém. Quem é infiel a si mesmo o é desculpavelmente a seu mestre. Mas assim são os príncipes, que não aceitam homens pela metade e desprezam os serviços limitados e condicionados. ${ }^{41}$

Nesse trecho, mais uma vez, Montaigne fala de si com os recursos estilísticos de alguém confessando suas deficiências, mas o possível intento dessa autodeclaração há de transpor essa esfera meramente pessoal e se erigir como crítica às pretensões morais de entrega desbragada aos comandos do Estado. Em verdade, por vezes, encontramos no texto dos "Ensaios" a proposta de uma obediência cega a todas as determinações do Estado. Há no livro a admissão de uma premissa legalista de que as leis devem ser obedecidas por serem leis, a despeito de serem justas ou não: "Ora as leis se mantêm em crédito não porque elas são justas, mas porque são leis. É o fundamento místico de sua autoridade, elas não têm qualquer outro!" ${ }^{2}$ No capítulo I, 23, "Sobre o costume e sobre não mudar facilmente uma lei recebida", essa visão é irrestrita, usando inclusive o exemplo de Sócrates...

A sociedade pública nada tem a fazer sobre nossos pensamentos, mas o restante, como nossas ações, nosso trabalho, nossas riquezas e nossa própria vida, é necessário a ela

40 Montaigne, III, 1, p. 791: “[B] Le bien public requiert qu'on trahisse, et qu'on mente, [C] et qu'on massacre: [B] resignons cette commission à gens plus obeissants et plus soupples. [C] II faut laisser jouer cette partie, aux citoyens plus vigoureus, et moins craintifs, qui sacrifient leur honneur et leur conscience, comme ces autres anciens sacrifierent leur vie, pour le salut de leur pays."

41 Montaigne, III, 1, p. 794B: “Je ne veux estre tenu serviteur, ny si affectionné, ny si loyal, qu'on treuve bon à trahir personne. Qui est infidelle à soy-mesme, l'est excusablement à son maistre. Mais ce son Princes; qui n'acceptent pas les hommes à moytié, et mesprisent les services limitez et conditionnez." Green (2012, pp. 124-5) com perspicácia fala do erro da edição de Villey em colocar vírgula onde na verdade Montaigne na camada $\mathrm{C}$ acrescenta ponto e vírgula no intuito de realçar que todo príncipe é assim.

42 “Or les loix se maintiennent en credit, non par ce qu'elles sont justes, mais par ce qu'elles sont loix. C'est le fondement mystique de leur authorité; elles n'en ont poinct d'autre!" III, 13, p. 1072B. 
prestar-se e abandonar-se a seu serviço e às opiniões comuns, como este bom e grande Sócrates recusou salvar sua vida pela desobediência do magistrado, mesmo de um magistrado deveras injusto e iníquo. ${ }^{43}$

... ao passo que a camada $\mathrm{B}$ (edição de 1588) ressalva o crédito formal às leis com um limite: ao contrário do que fez Sócrates, Montaigne confessa que jamais optaria pela obediência às leis em detrimento da própria vida e que o sábio grego teria incorrido em exageros legalistas; o que não acarreta a mera desobediência, mas sim a evasão:

[...] o sábio Dandamis, ouvindo recitar as vidas de Sócrates, Pitágoras, Diógenes, os julgou grandes personagens em todas as outras coisas, mas muito submissos à reverência das leis; para lhes autorizar e seguir, a verdadeira virtude tem muito a se reduzir de seu vigor original. ${ }^{44}$

Cumpre notar que, como em muitos outros tópicos, a "Apologia de Raymond Sebond" posiciona-se como um ponto crítico de viragem. Nesse ensaio, há uma crítica cética, já na primeira edição publicada, à atitude legalista, em consideração ao fato de que as leis podem ser voláteis:

Nessa necessidade que nos dirá a filosofia? Que nós sigamos as leis de nosso país? Isto é, esse mar flutuante de opiniões de um povo ou de príncipe, que me pintarão a justiça com tantas cores e a reformarão em tantas faces que não haverá nelas mudanças de paixão? Eu não posso ter um julgamento tão flexível. ${ }^{45}$

Já no livro III, lemos: "Se aquelas [leis] a quem sirvo me ameaçassem somente à ponta do dedo, eu sem contenção iria embora encontrar outras". ${ }^{46}$ Montaigne também acata a possibilidade de evasão no caso de uma potencial dilaceração ou inconsistência nas leis ou no entrechoque de poderes dominantes. Se não houver clareza sobre o que obedecer, seria melhor evadir-se. ${ }^{47}$ Assim,

43 Montaigne, I, 23, p. 118: "La societé publique n'a que faire de nos pensées; mais le demeurant, comme nos actions, nostre travail, nos fortunes et nostre vie propre, il la faut préter et abandonner à son service et aux opinions communes, comme ce bon et grand Socrates refusa de sauver sa vie par la desobeissance du magistrat, voire d'un magistrat tres-injuste et tres-inique."

44 Montaigne, II, 1, p. 796B: "si que le sage Dandamys, oyant reciter les vies de Socrates, Pythogoras, Diogenes, les jugea grands personnages en toute autre chose, mais trop asservis à la reverence des loix, pour lesquelles auctoriser et seconder, la vraye vertu a beaucoup à se desmettre de sa vigueur originelle".

45 "Que nous dira donc en cette necessité la philosophie? Que nous suyvons les loix de nostre pays? c'est à dire cette mer flotante des opinions d'un peuple ou d'un Prince, qui me peindront la justice d'autant de couleurs et la reformeront en autant de visages qu'il y aura en eux de changemens de passion? Je ne puis pas avoir le jugement si flexible." (MONTAIGNE, II, 12, p. 579A).

46 Montaigne, III, 13, p. 1072B: "Si celles que je sers me menassoient seulement le bout du doigt, je m'en irois incontinent en trouver d'autres".

47 III, 9, p. 994B: "Autant que l'image des loix receues et antiennes de cette monarchie reluyra en quelque coin, m'y voilà planté. Si elles viennent par malheur à se contredire et empescher entr'elles, et produire deux pars de chois doubteux et difficile, mon election sera volontiers d'eschapper et me desrober à cette tempeste [...]". 
passagens como essa desdizem a afirmação de alguns intérpretes, como Gilmar Conceição (2014, p. 358), de que "Montaigne permanece estritamente legalista".

Creio que seria enfraquecer a força e o valor da introspecção de Montaigne interpretar que essas declarações não infirmam o legalismo geral nos Ensaios pretendidamente por se tratar apenas de uma "volta a si". ${ }^{48}$ É verdade que Montaigne redige todas essas ocorrências textuais em tom de confissão pessoal e não de prescrição universal. Contudo, ao falar de si, Montaigne fala de suas opiniões e vice-versa. A rejeição montaigniana do respeito cego de Sócrates às leis, inclusive, abriu uma linhagem crítica importante nos séculos seguintes. ${ }^{49}$

Esse distanciamento em relação ao mártir da filosofia não consiste em uma reles confissão de temor pessoal: "Muitos desses raros exemplos [como o de Sócrates] ultrapassam a força de minha ação, mas alguns ultrapassam também a força de meu julgamento". ${ }^{50}$ Montaigne está, com isso, restringindo a aceitabilidade formal das leis até o limite da vida ou das pessoas a ela submetidas (e da coerência entre elas). Para ser mais exato, Montaigne está, nesse ponto, incluindo nas restrições formais de aceitação das leis os limites da vida ou da disposição em abdicar da vida dos indivíduos a elas submetidos. Parece-me que em consonância com a ideia embrionária de uma autopertença individual, presente nos Ensaios, Montaigne teria levantado suspeitas ao uso do indivíduo pelo Estado e lançado os gérmens de uma visão em que não apenas o indivíduo tem deveres ante as exigências do Estado, mas também esse último deveres fundamentais perante o primeiro.

A suspeita de Montaigne perante os atos de coragem gradativamente - ao longo dos vinte anos de escrita dos "Ensaios" - assume as feições mais amplas e mais contundentes de uma suspeita quanto à participação dos indivíduos na qualidade de lenha ou acendedores para a fogueira de monstruosidades sociais, tais como a guerra entre religiões.

\section{Referências}

ARAÚJO, S. X. G. “Uma leitura de da glória e Da presunção nos ensaios de Montaigne”. Rio de Janeiro. 207ff. Tese (História). PUC-Rio, 2008.

. "Glória, Presunção e o projeto do autorretrato nos Ensaios de Montaigne". $O$ que nos faz pensar, Nr. 27, pp. 309-23, maio 2010.

ARISTÓTELES. "Ética a Nicômaco". In: Aristóteles. Tradução de L. Vallandro e G. Bornheim. São Paulo: Abril Cultural, 1984. Col. Os Pensadores. 
. "The Eudemian Ethics". Translated by H. Rackham. Cambridge, London: Harvard University Press, 1996. The Loeb Classical Library.

BENCIVENGA, E. "The Discipline of Subjectivity: an essay on Montaigne". Princeton: Princeton UP, 1990.

BONADEO, A. "Montaigne on War". Journal of the History of Ideas, Vol. 46, Nr. 3, pp. 417-426, Jul.-Sep. 1985.

BOON, J.-P. "Montaigne: gentilhomme et essayiste". Paris: Ed. Universitaires, 1971. BRAHAMI, F. "Le travail du scepticisme". Paris: PUF, 2001.

BUTOR, M. "Essais sur les Essais". Paris: Gallimard, 1968.

CAVAILLÉ, J.-P. "Socrate libertin". In: LOJACONO, E. (org.). Socrate in Occidente. Firenze: Le Monnier Università, 2004. pp. 33-65.

CONCEIÇÃO, G. H. "Montaigne e a política". Cascavel: EdUnioeste, 2014.

DURKHEIM, E. "Le suicide: étude sociologique”. Paris: PUF, 1997.

FRIEDRICH, H. "Montaigne". Bern: Francke, 1949.

GREEN, F. "Montaigne and the Life of Freedom". New York: Cambridge University Press, 2012.

KONSTANTINOVIC, I. “Montaigne et Plutarque”. Genève: Droz, 1989.

MERLEAU-PONTY, M. [1960]. “Lecture de Montaigne”. In: Oeuvres. Paris: Gallimard, 2010. pp. 1349-1362.

MONTAIGNE, M. “Les Essais”. Ed. Villey-Saulnier. Paris: PUF, 1998. 3 Vols. . "Os Ensaios". Tradução de R. C. Abílio. São Paulo: Martins Fontes, 20002001. 3 Vols.

PLUTARCO. "Vie de Caton d'Utique". In: Les vies des hommes illustres. Tradution Jacques Amyot. Paris: Gallimard, 1951.

QUINT, D. "Montaigne and the suicide bombers: a discussion of "De la Vertu"'. The Yale Review, Vol. 97, Nr. 4, pp. 73-84, Oct. 2009.

SCHAEFER, D. L. "The Political Philosophy of Montaigne". Ithaca, London: Cornell University Press, 1990.

SCORALICK, A. "Experiência e Moralidade no último dos Ensaios de Montaigne". Dissertação (Filosofia), São Paulo, USP, 2008, 148f.

STAROBINSKI, J. “Montaigne en mouvement". Paris: Gallimard, 1982.

TENENTI, A. "Il senso della morte e l'amore della vita nel Rinascimento: Francia e Italia". Turim: Einaudi, 1957.

THIBAUDET, A. "Montaigne". Paris: Gallimard, 1963.

VAZ, L. “A simulação da morte: versão e aversão em Montaigne”. São Paulo: Perspectiva, 2011. 